\title{
Extraparenchymal neurocysticercosis: a challenge in treatment and in clinical management
}

\section{Neurocisticercosis extraparenquimal: Un desafío en el tratamiento y en el manejo clínico}

\author{
Agnès Fleury \\ Instituto de Investigaciones Biomédicas, UNAM (México) \\ Edda Sciutto ${ }^{1}$ \\ Instituto de Investigaciones Biomédicas, UNAM (México)
}

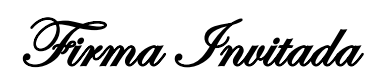

Recibido: 19 de marzo de 2020

Aceptado: 25 de mayo de 2020

Publicado: 03 de junio de 2020

\section{Resumen}

La neurocisticercosis es una enfermedad correspondiente a la localización de la forma larvaria del parásito Taenia solium (cisticerco) en el sistema nervioso central. Este artículo describe el desafío que continúa en el tratamiento de la forma más severa de neurocisticercosis que ocurre cuando el parásito se instala fuera del parénquima. Se discute la relevancia del control de la neuroinflamación para la supervivencia del paciente y sus implicaciones en la efectividad del tratamiento.

Palabras clave: neurocisticercosis, tratamiento, fármacos cesticidas, neuroinflamación

${ }^{1}$ Email: $\underline{\text { edda@unam.mx }}$

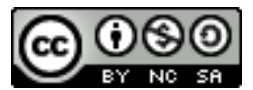

Revista del Centro de Investigación. Universidad La Salle por Dirección de Posgrado e Investigación. Universidad La Salle Ciudad de México se distribuye bajo una Licencia Creative Commons AtribuciónNoComercial-Compartirlgual 4.0 Internacional 
Fleury, A.; Sciutto E.

\section{Abstract}

Neurocysticercosis is a parasitic disease that occurs when cysticerci are installed in the central nervous system. This paper describes the challenge that continues in the treatment of the most severe form of neurocysticercosis that occurs when the parasite is installed outside the parenchyma. The relevance of neuroinflammation control for patient survival and its implications on the effectiveness of the treatment are discussed.

Keywords: neurocysticercosis; treatment; cysticidal drugs; neuroinflammation 


\section{Introduction}

Taenia solium (Ts) cysticercosis is a parasitic infection acquired by humans and pigs (the intermediary hosts) after ingesting the parasite eggs, released to the environment by human tapeworm carriers. Humans (the definitive hosts) acquire intestinal tapeworms by eating insufficiently cooked meat from cysticercotic pigs (Sciutto et al., 2000). A single tapeworm produces tens of thousands of eggs per day, which are shed to the environment (vegetables, running waters, soils) upon human tapeworm carrier open-air defecation practice. T. solium is endemic in most of the non-developed countries of Latin America, Africa and Asia, where all the conditions that favor transmission persist i.e., pigs rustically reared, inadequate and insufficient meat inspection and drainage and limited or no access to sanitary services (De Aluja, 2008).

In human, the most frequent form of the disease is Neurocysticercosis (NCC) that occurs when cysticerci (larval form of Taenia solium) are installed in the central nervous system (CNS).

\section{Neurocysticercosis: A pleomorphic disease}

NCC is an extremely pleomorphic disease (Coyle and Tanowitz, 2009; Fleury et al., 2010). In rural communities that present condition that favor transmission, it has been reported that almost $10 \%$ of the inhabitants have radiological lesions compatible with asymptomatic calcified parenchymal neurocysticercosis (Fleury et al., 2003; 2006). This is not surprising considering that immunological evidences support that more than $90 \%$ of the inhabitants have been in contact with the parasite (Chavarria et al., 2003). The absence of symptoms is expected since parenchymal NCC (P-NCC) is a benign form of the disease (Figure 1). In P-NCC the parasite tends to be destroyed probably by effective host immunity and in most cases evolves with mild or absence of symptoms. Epilepsy, the most important symptom in P-NCC, can generally be well controlled using anti-epileptic drugs (Duque and Burneo, 2017). However, it has been reported that the evolution can be improved by cysticidal treatment. Albendazole and Praziquantel are the drugs more extensively used for NCC 
treatment. It was shown recently that the use of a combination of $\mathrm{ABZ}$ and PZQ is more efficient for these patients than one of them used alone in case of multiple parenchymal parasites (Garcia et al., 2016).
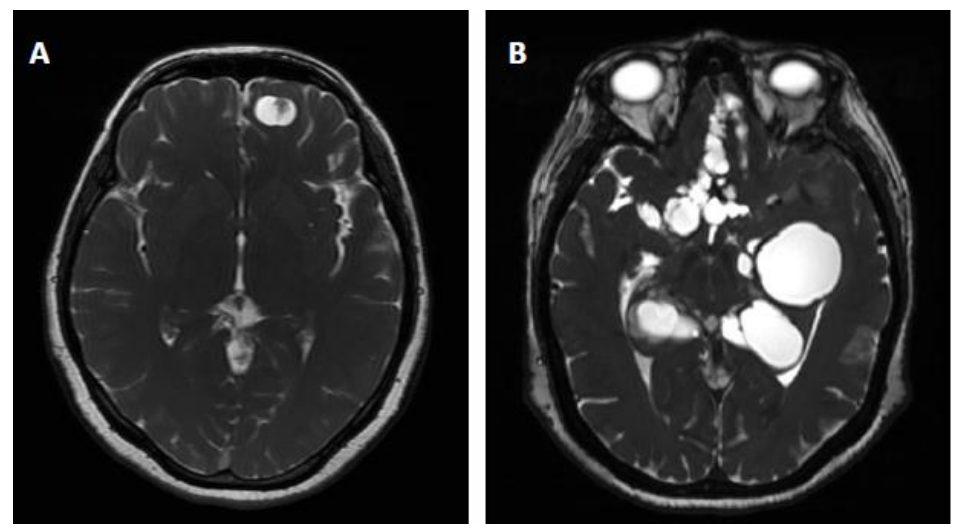

Figure 1. Radiological aspect of Neurocysticercosis caused by parenchymal (A) or extraparenchymal (B) cysticerci

\section{Extraparenchymal neurocysticercosis: a severe neurological disease}

A completely different scenario, much more worrying, occurs when the parasite is installed in the cerebral extraparenchymal region (ExP-NCC), mostly in the subarachnoid space of the basal cisterns and in the ventricular system (Fleury et al., 2011). The Figure 1b illustrates this form of NCC, where multiple cysticerci occupy the basal cisterns. Probably, as in these locations parasites have more space to growth, their size at diagnosis is generally much higher than in other cerebral areas. Symptoms are more severe; particularly more of $70 \%$ of the patients developed intracranial hypertension due to the perturbation of the circulation of the cerebrospinal fluid (CSF) caused by the presence of the parasite (Marcin-Sierra et al., 2017). This situation can compromise the life of the patient and generally require the colocation of a ventriculoperitoneal shunt (Osorio et al., 2019).

\section{Extraparenchymal neurocysticercosis: treatment}

In 2017, Clinical Practice Guidelines for the Diagnosis and Treatment of NCC were published (White et al., 2017). Although this effort must be highlighted, it is evident that 
for the moment enough information are lacking to strongly recommend precise therapeutic scheme for extraparenchymal NCC (Carpio et al., 2018). Particularly, we can note that in these Guidelines, on the eleven recommendations made regarding treatment of extraparenchymal NCC (ventricular and subarachnoid), 6 of them (54.5\%) have a low quality of evidence and a weak strength of recommendation (White et al., 2017). More clinical trials are urgent to made to determine with more strength and certainty the best management for these patients, as the problem is evident. Indeed, more than $50 \%$ of ExPNCC patients are non-responders to the cysticidal treatment and require several cycles of albendazole to damage the parasite (Marcin Sierra et al., 2017; Osorio et al., 2019). ExPNCC patients also have an exacerbated central inflammation that can be aggravated by increased antigen release with treatment-mediated damage to the parasite. This exacerbated inflammation is likely to damage the blood-brain barrier and promote antigen release that may induce in the periphery the production of regulatory cells to control it (Fleury et al., 2016). As the result we find in the blood and in the CSF of these patients an increase in Tregs accompanied by high levels of IL10 (Adalid-Peralta et al., 2012; Arce-Sillas et al., 2016). However, the central and peripheral increased of Tregs is not enough to control neuroinflammation and cysticidal drugs must be administered with glucocorticoids to avoid the inflammatory complications (mainly arachnoiditis and vasculitis) and intracranial hypertension (Toledo et al., 2018). Glucocorticoids (GCs), dexamethasone or prednisone, are the first-line drugs used for this purpose. However, with oral or endovenous administration only a low fraction of GC reaches the central nervous system (Meneses et al., 2019). Thus, high systemic doses are required for brain-specific targeting causing severe undesirable effects. To avoid this, alternative anti- inflammatory drugs like Methotrexate has been used (Mitre et al., 2007), in particular in diabetic patients. Other new therapies based on the use of antibodies against anti-tumor necrosis factor are also explored but it is not a realistic tool in non-developing countries (most of the endemic countries) considering the high costs of this therapy (Nash et al., 2019). The lack of experimental models of neurocysticercosis has limited the evaluation of possible immunomodulators that could be used for the finer control of neuroinflammation. Recently, a model of Ex-P-NCC in rats caused by the Taenia crassiceps cysticercus has 
been published. This new model will make it possible to carry out the research necessary to advance with new alternatives for the control of neuroinflammation in ExP-NCC (Hamamoto Filho et al., 2019).

Therefore, as seen, in these NCC forms we have a double therapeutical challenge: partial efficacy of the cysticidal treatment and non-optimal anti-inflammatory treatment. There is an urgent need to improve this current therapeutic approach. On the other hand, different evidences indicate that a certain degree of inflammation improve the effect of cysticidal drugs (Cárdenas et al., 2014; Toledo et al., 2018; Palomares-Alonso et al., 2020). Thus, we are in a complex situation, in which we must finely regulate the neuroinflammatory phenomenon, by reducing the elements involved in the generation of complications but by favoring those which participate in the success of cysticidal treatment (Toledo et al., 2018). A better understanding of the neuroinflammatory phenomenon and its relationship with the disease should make it possible to improve the current NCC therapeutic management. In particular, the central / periphery communication of the inflammatory phenomenon should make possible to find peripheral markers, which will be of great help in regulating the anti- inflammatory treatment

\section{Conclusions and Perspectives}

The treatment of ExP-NCC continues to be a challenge. Although there are drugs that in principle are efficient for the destruction of cysticercus, these do not work in an optima manner in a large part of cysticerci located outside the parenchyma. Evidences point that neuroinflammation should be regulated more carefully to increase the effectiveness of cysticidal treatment. To optimize the treatment of this severe form of NCC, future investigations should focus on finding peripheral markers to monitor the characteristics of the central inflammatory response, as well as developing effective anti-inflammatory drugs at low cost and with less collateral effects than the systemic GC currently available. 


\section{Acknowledgments}

This study was supported by the "Programa para el desarrollo de vacunas, inmunomoduladores y métodos diagnósticos”, Instituto de Investigaciones Biomédicas de la Universidad Nacional Autónoma de México.

The authors have no conflict of interests. 


\section{References}

Adalid-Peralta L., Fleury A., García-Ibarra T.M., Hernández M., Parkhouse M, Crispín J.C., Voltaire-Proaño J., Cárdenas G., Fragoso G., Sciutto E. (2012). Human neurocysticercosis: in vivo expansion of peripheral regulatory $\mathrm{T}$ cells and their recruitment in the central nervous system. $J$ Parasitol, 98(1):142-148. doi: http://doi.org/10.1645/GE-2839.1

Arce-Sillas A., Álvarez-Luquín D., Cárdenas G., Casanova-Hernández D., Fragoso G., Hernández M., Proaño Narváez J., García-Vázquez F., Fleury A., Sciutto E., AdalidPeralta L. (2016). Interleukin 10 and dendritic cells are the main suppression mediators of regulatory T cells in human neurocysticercosis. Clin Exp Immunol, 183(2):271-279. doi: http://doi.org/10.1111/cei.12709

Cárdenas G., Fragoso G., Rosetti M., Uribe-Figueroa L., Rangel-Escareño C., Saenz B., Hernández M., Sciutto E., Fleury A. (2014). Neurocysticercosis: the effectiveness of the cysticidal treatment could be influenced by the host immunity. Med Microbiol Immunol, 203(6):373-381. doi: http://doi.org/10.1007/s00430-014-0345-2

Carpio A., Fleury A., Kelvin E. A., Romo M. L., Abraham R., Tellez-Zenteno J. (2018). New guidelines for the diagnosis and treatment of neurocysticercosis: a difficult proposal for patients in endemic countries. Expert Rev Neurother, 18(10):743-747. doi: http://doi.org/10.1080/14737175.2018.1518133

Chavarría A., Roger B., Fragoso G., Tapia G., Fleury A., Dumas M., Dessein A., Larralde C., Sciutto E. (2003). TH2 profile in asymptomatic Taenia solium human neurocysticercosis. Microbes Infect, 5(12), 1109-1115.

Coyle C. M., Tanowitz H. B. (2009). Diagnosis and treatment of neurocysticercosis. Interdiscip Perspect Infect Dis, 180742. doi: http://doi.org/10.1155/2009/180742

de Aluja A. S. (2008). Cysticercosis in the pig. Curr Top Med Chem, 8, 368-374.

Duque K. R., Burneo J. G. (2017). Clinical presentation of neurocysticercosis-related epilepsy. Epilepsy Behav, 76, 151-157.

Fleury A., Gomez T., Alvarez I., Meza D., Huerta M., Chavarria A., Carrillo Mezo R. A., Lloyd C., Dessein A., Preux P.M., Dumas M., Larralde C., Sciutto E., Fragoso G. 
(2003). High prevalence of calcified silent neurocysticercosis in a rural village of Mexico, Neuroepidemiology. 22, 139-145.

Fleury A., Morales J., Bobes R.J., Dumas M., Yanez O., Pina J., Carrillo-Mezo R., Martinez J. J., Fragoso G., Dessein A., Larralde C., Sciutto E. (2006). An epidemiological study of familial neurocysticercosis in an endemic Mexican community, Trans $R$ Soc Trop Med Hyg. 100, 551-558.

Fleury A., Escobar A., Fragoso G., Sciutto E., Larralde C. (2010). Clinical heterogeneity of human neurocysticercosis results from complex interactions among parasite, host and environmental factors. Trans R Soc Trop Med Hyg. 104(4), 243-250.

Fleury A., Carrillo-Mezo R., Flisser A., Sciutto E., Corona T. (2011). Subarachnoid basal neurocysticercosis: a focus on the most severe form of the disease. Expert Rev Anti Infect Ther, 9(1):123-133. doi: http://doi.org/10.1586/eri.10.150 .

Fleury A., Cardenas G., Adalid-Peralta L., Fragoso G., Sciutto E. (2016). Immunopathology in Taenia solium neurocysticercosis. Parasite Immunol, 38(3):147-157. doi: http://doi.org/10.1111/pim.12299

Garcia H. H., Lescano A. G., Gonzales I., Bustos J. A., Pretell E. J., Horton J., Saavedra H., Gonzalez A. E., Gilman R. H. Cysticercosis Working Group in Peru. (2016). Cysticidal Efficacy of Combined Treatment With Praziquantel and Albendazole for Parenchymal Brain Cysticercosis. Clin Infect Dis, 62(11),1375-1379.

Hamamoto Filho P. T., Fogaroli M. O., Oliveira M.A.C., Oliveira C., Setembre Batah S., Todorovic Fabro A., Vulcano L. C., Bazan R., Zaniniet M. A. (2019). A Rat Model of Neurocysticercosis-Induced Hydrocephalus: Chronic Progressive Hydrocephalus with Mild Clinical Impairment. World Neurosurg, 132:e535-e544.

Marcin Sierra M., Arroyo M., Cadena Torres M., Ramírez Cruz N., García Hernández F., Taboada D., Galicia Martínez A., Govezensky T., Sciutto E., Toledo A., Fleury A. (2017). Extraparenchymal neurocysticercosis: Demographic, clinicoradiological, and inflammatory features. PLoS Negl Trop Dis, 11(6), e0005646.

Meneses G., Cárdenas G., Espinosa A., Rassy D. Pérez-Osorio I., Bárcena B., Fleury A., Besedovsky H., Fragoso G., Sciutto E. (2019). Sepsis: developing new alternatives to reduce neuroinflammation and attenuate brain injury. Ann N Y Acad Sci. 1437(1):4356. doi: http://doi.org/10.1111/nyas.13985 
Nash T. E., Ware J. M., Coyle C. M., Mahanty S. (2019). Etanercept to Control Inflammation in the Treatment of Complicated Neurocysticercosis. Am J Trop Med Hyg, 100(3):609-616.

Osorio R., Carrillo-Mezo R., Romo M. L., Toledo A., Matus C., González-Hernández I., Jung H., Fleury A. (2019). Factors Associated With Cysticidal Treatment Response in Extraparenchymal Neurocysticercosis. J Clin Pharmacol, 59(4):548-556.

Palomares-Alonso F., Toledo A., Palencia Hernández G., Jung-Cook H., Fleury A. (2020). Effect of dexamethasone on albendazole cysticidal activity in experimental cysticercosis by Taenia crassiceps in BALB/c mice: In vitro and in vivo evaluation. Exp Parasitol, 208:107801. doi: http://doi.org/10.1016/j.exppara.2019.107801

Sciutto E., Fragoso G., Fleury A., Laclette J. P., Sotelo J., Aluja A., Vargas L., Larralde C. (2000). Taenia solium disease in humans and pigs: an ancient parasitosis disease rooted in developing countries and emerging as a major health problem of global dimensions. Microbes Infect, 2,1875-1890.

Toledo A., Osorio R., Matus C., Martinez Y., Ramirez Cruz N., Sciutto E., Fragoso G., Arauz A., Carrillo-Mezo R., Fleury A. (2018). Human Extraparenchymal Neurocysticercosis: The Control of Inflammation Favors the Host...but Also the Parasite. Front Immunol. 9, 2652, 1-14. doi: http://doi.org/10.3389/fimmu.2018.02652

White A.C. Jr, Coyle C. M., Rajshekhar V., Singh G., Hauser W., Mohanty A., Garcia H., Nash T. (2018). Diagnosis and Treatment of Neurocysticercosis: 2017 Clinical Practice Guidelines by the Infectious Diseases Society of America (IDSA) and the American Society of Tropical Medicine and Hygiene (ASTMH). Clin Infect Dis, 66(8):1159-1163. doi: http://doi.org/10.1093/cid/ciy15 